\title{
Buckling Behavior of Sandwich Panel with Isotropic Core and Orthotropic Faces
}

\author{
Saheel Arshad, Abhay Kumar Chaubey
}

\begin{abstract}
A sandwich panel is a lightweight structure, economical and having low thermal conductivity. It is made up of three layers in which the middle layer is called core which is bounded with thin layers at top and bottom called faces. Generally, the core has relatively low-density which makes it lightweight. The buckling load analysis of sandwich panel having isotropic core and orthotropic faces is studied for different support conditions using the FE based software ABAQUS. The FE model is validated with suitable published results. Then it is used to find critical buckling load of sandwich panel with isotropic core and orthotropic faces. Many new results have been presented for different thickness, end conditions, aspect ratio, etc.
\end{abstract}

Keywords: Terms: sandwich panel, buckling behavior, ABAQUS

\section{INTRODUCTION}

Sandwich panels (Fig. 1 and Fig. 2) subjected to uniaxial buckling are used in numerous engineering applications like structural, marine, aerospace, and others. Sandwich panel is used as a roofing unit in the airport, hanger, large column-free area, and marine structure. Sandwich panels are prominent because of the lightweight and low thermal conductivity. Different boundary combinations of Sandwich roofs/walls are used in construction practice. Buckling of Sandwich panels subjected to compressive loads is one of the normal failure modes and it is important to calculate the crucial buckling load for the safe design of the structure.

Construction of the building is a big challenge to civil engineers and the government especially in developing countries throughout the world. This problem is due to the dense concentration of the population in urban areas. It is a very difficult task to meet the challenges in the construction practices; however, it is a big challenge to the civil engineers to meet the housing demand in a short span without compromising on the quality. Traditional building construction is inadequacy so a new building system was developed at the beginning of the $20^{\text {th }}$ century. So we have to use different alternative materials to decrease the concrete portion and to save the environment [1]. A Sandwich is a new

Revised Manuscript Received on February 05, 2020.

* Correspondence Author

Saheel Arshad*, Department of Civil Engineering, Koneru Lakshmaiah Education Foundation (Deemed to be University), Vaddeswaram, Guntur district, Andhra Pradesh, India.

Abhay Kumar Chaubey, Department of Civil Engineering, Koneru Lakshmaiah Education Foundation (Deemed to be University), Vaddeswaram, Guntur district, Andhra Pradesh, India.

(C) The Authors. Published by Blue Eyes Intelligence Engineering and Sciences Publication (BEIESP). This is an open access article under the CC BY-NC-ND license (http://creativecommons.org/licenses/by-nc-nd/4.0/)

construction technology which was used by William Fairbairn in the year 1849.

The sandwich panel system is used around the world for low rise and high rise commercial structures. According to the architecture and structural point of view, the precast concrete sandwich panels are widely used [2]. Pokharel and Mahendran [3] studied the buckling effects of Australian sandwich plates by experimental and FE analysis with ABAQUS. Pokharel and Mahendran [4] studied local buckling effects of sandwich panel with Polystyrene foam core and steel faces subjected to bending and axial compression. Taczała and Banasiak [5] investigated the buckling of I-core panels which are subject to compressive loading with local buckling modes. Elasticity solution for buckling of sandwich panels under the uniaxial buckling load was studied by Kardomateas [6]. He derived the pre-buckling solution for the orthotropic phases for face and core. Kolsters and Zenkert [7] studied buckling of laser-welded sandwich panels using a finite element (FE) software ABAQUS. Indentation of aluminium foam core sandwich panel was investigated using finite element model developed in ABAQUS by $\mathrm{Xu}$ et al [8]. They compared their simulation results and experimental results with various thickness of foam and bottom face constrained. Chakrabarti et al. [9] presented buckling analysis of soft-core sandwich beam using the co-efficient FE model and calculated critical buckling loads for multi-layered sandwich beam having soft-core. The behavior of sandwich structures [10-11] and recent FE studies [12-25] have been studies by many researchers.

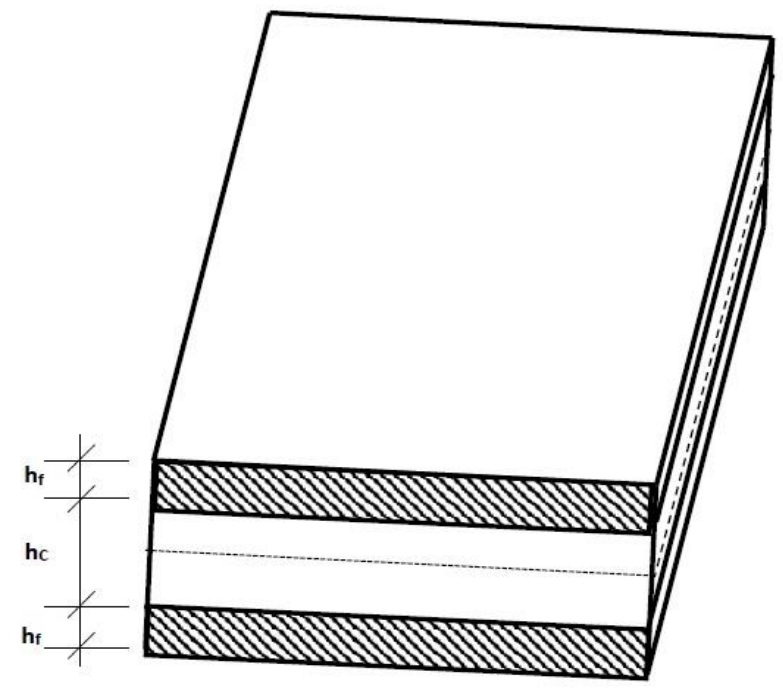

Fig. 1: Sandwich panel 


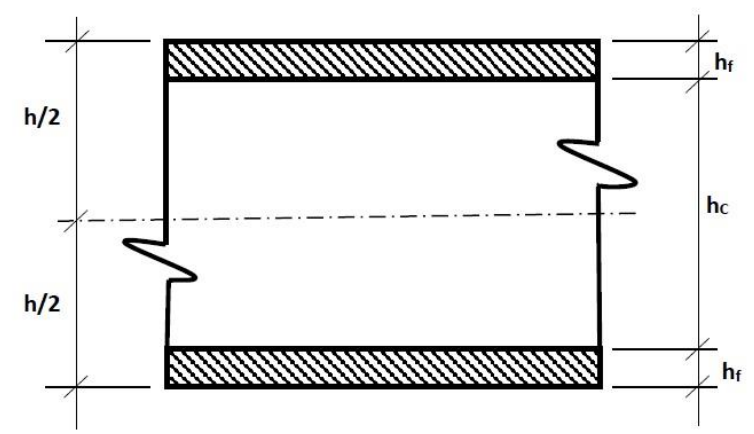

Fig. 2 Cross-section of sandwich panel

\section{Research Significance}

Sandwich panels having isotropic core and orthotropic faces are lightweight, stiff and have good thermal properties. The sandwich panel absorbs heat and it also acts as an insulation material. Sandwich panel is having similar properties as compared to precast wall panels in terms of cost, durability, fire resistance and it can also be used as a shear wall, retaining wall and bearings walls. It can be used in the building expansion if needed. It is light in weight and easy to construct and it reduces the usage of concrete. Thus, for the safe design of the sandwich structure, an FE model is required to solve various buckling problems with precision and with a less computational cost. And also the effect of end conditions, aspect ratio and thickness is beneficial for researchers and for designers.

\section{METHODOLOGY}

The mathematical model in ABAQUS is as follows: $\{A\}=\{B\}+z\{C\}$ where $\{A\}=\left\{\begin{array}{l}u \\ v \\ w\end{array}\right\} ;\{B\}=\left\{\begin{array}{l}u_{0} \\ v_{0} \\ w_{0}\end{array}\right\}$ and $\{C\}=\left\{\begin{array}{c}\theta_{x} \\ \theta_{y} \\ \theta_{z}\end{array}\right\}$ $\{A\}$ is displacement, $\{B\}$ is mid-plane displacement along with the $(\mathrm{x}, \mathrm{y}, \mathrm{z})$ coordinates and $\{C\}$ is rotation.

The strain vector:

$\{\varepsilon\}=\left\{\varepsilon_{0}\right\}+z\{K\}$

where $\{\varepsilon\}=\left\{\begin{array}{l}\varepsilon_{x} \\ \varepsilon_{y} \\ \varepsilon_{z} \\ \gamma_{x y} \\ \gamma_{y z} \\ \gamma_{z x}\end{array}\right\} ;\left\{\varepsilon_{0}\right\}=\left\{\begin{array}{c}\varepsilon_{x 0} \\ \varepsilon_{y 0} \\ \varepsilon_{z 0} \\ \gamma_{x y 0} \\ \gamma_{y z 0} \\ \gamma_{z x 0}\end{array}\right\}=\left\{\begin{array}{c}\frac{\delta u_{0}}{\delta x} \\ \frac{\delta v_{0}}{\delta y} \\ 0 \\ \frac{\delta u_{0}}{\delta y}+\frac{\delta v_{0}}{\delta x} \\ \frac{\delta w_{0}}{\delta y}+\theta_{y} \\ \frac{\delta w_{0}}{\delta x}+\theta_{x}\end{array}\right\}$ and

$$
\{K\}=\left\{\begin{array}{c}
K_{x} \\
K_{y} \\
K_{z} \\
K_{x y} \\
K_{y z} \\
K_{z x}
\end{array}\right\}=\left\{\begin{array}{c}
\frac{\delta \theta_{x}}{\delta x} \\
\frac{\delta \theta_{y}}{\delta y} \\
0 \\
\frac{\delta \theta_{x}}{\delta y}+\frac{\delta \theta_{y}}{\delta x} \\
\frac{\delta \theta_{x}}{\delta y} \\
\frac{\delta \theta_{y}}{\delta x}
\end{array}\right\}
$$

The governing equation for buckling analysis: $\left\{[K]-\lambda[K]_{\mathrm{G}}\right\}\{\delta\}=\{0\}$

where $\{\delta\}$ is the nodal displacement vector, $[K]$ is the linear stiffness matrices, $\lambda$ is the critical buckling load and $[K]_{G}$ is the geometric stiffness matrices.

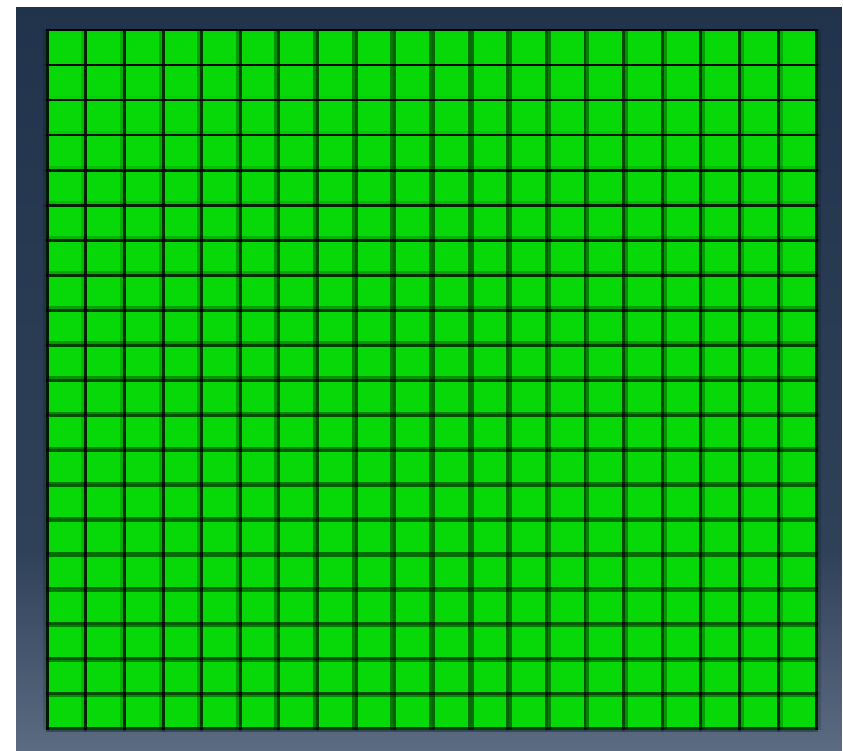

Fig. 3. The meshing of sandwich panel

\section{RESULTS AND DISCUSSION}

\section{Convergence and Comparison Study:}

The accuracy of the present FE model developed using ABAQUS has been validated with Kheirikhah et al. [26] [Table 1]. For convergence and comparison study a simply supported sandwich panel has been considered. The sandwich panel has been divided into 20 × 20 elements [Figure 3]. The material property and nondimensional formula have been taken from Kheirikhah et al. [26]. 
Table 1: Convergence and validation study

\begin{tabular}{ll}
\hline Mesh size & $\begin{array}{l}\text { Non-dimensional Buckling } \\
\text { load }\end{array}$ \\
\hline $12 \times 12$ & 5.9405 \\
$16 \times 16$ & 5.8021 \\
$18 \times 18$ & 5.7416 \\
20x20 & 5.7280 \\
\hline Kheirikhah et al. [26] & 5.6215 \\
\hline
\end{tabular}

Present Study:

After validation effect of end condition, aspect ratio and thickness have been studied using the present FE model.

The material properties used for the analysis is

For face:

$\mathrm{E}_{1}=40 \mathrm{E}, \mathrm{E}_{2}=\mathrm{E}, \mu_{12}=0.25, \mathrm{G}_{12}=0.6, \mathrm{G}_{23}=0.5, \mathrm{G}_{13}=0.6$

For core:

$\mathrm{E}_{1}=\mathrm{E}_{2}=0.04 \mathrm{E}, \mu=0.250$.

The buckling load parameter (non dimensional) used in the paper is $\frac{a^{2} \lambda}{E_{2} h^{3}}$

where ' $a$ ' is length and ' $h$ ' is thickness of the sandwich panel.

\section{Effect of end condition:}

In this subsection, the effect of end conditions on the non-dimensional buckling load has been studied on two types of sandwich panels $(0 / 90 / C / 90 / 0$ and $0 / C / 0)$. The effect of six practically possible boundary conditions has been presented in figure 4. It can be seen that clamped sandwich panel have highest non-dimensional buckling compared to others for both types of sandwich panel. CFCF sandwich panel has the lowest non-dimensional buckling load.

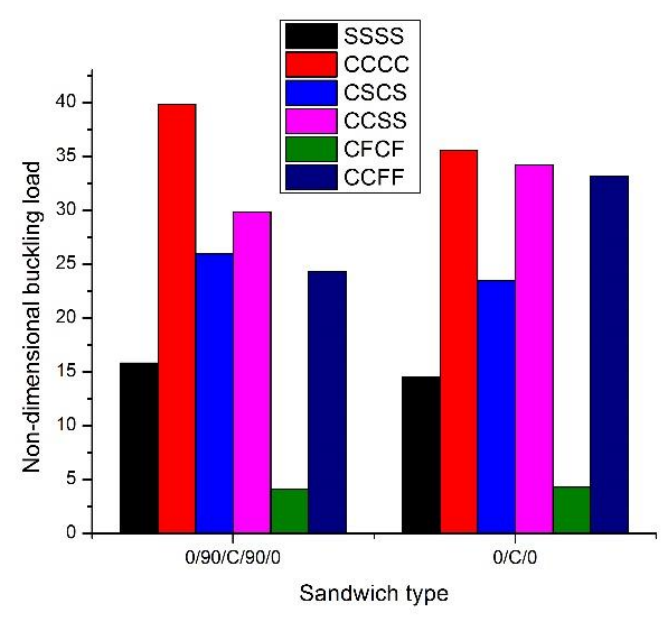

Fig. 4. Effect of end conditions on buckling of sandwich panels $(a / b=1$ and $\mathbf{a} / \mathbf{h}=20)$.

[S - Simply supported; C - Clamped; F - Free]

\section{Effect of aspect ratio:}

In this subsection, the effect of a/b ratio on a non-dimensional buckling load has been studied on two types of sandwich panels $(0 / 90 / \mathrm{C} / 90 / 0$ and $0 / \mathrm{C} / 0)$. Here, a/b values have been varied from 1 to 5 . It can be seen from figure 5 that with an increase in aspect ratio ( $\mathrm{a} / \mathrm{b}$ values) the non-dimensional buckling load increase for both types of sandwich panel.

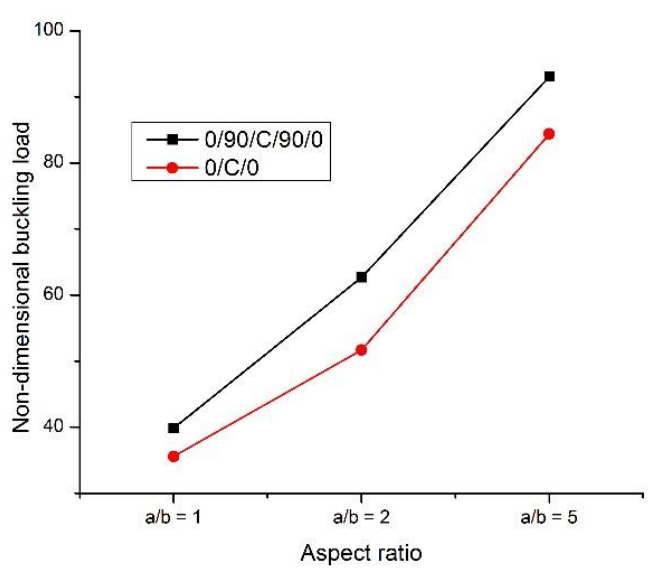

Fig. 5. Effect of aspect ratio on buckling of clamped sandwich panels $(a / h=20)$.

\section{Effect of thickness:}

In this subsection, the effect of $\mathrm{a} / \mathrm{h}$ ratio on the non-dimensional buckling load has been studied on two types of sandwich panels $(0 / 90 / C / 90 / 0$ and $0 / C / 0)$. Here a/h has been varied from 20 to 100. It can be seen from figure 6 that with an increase in a/h ratio, non-dimensional buckling load of sandwich panel with isotropic core and orthotropic faces increases

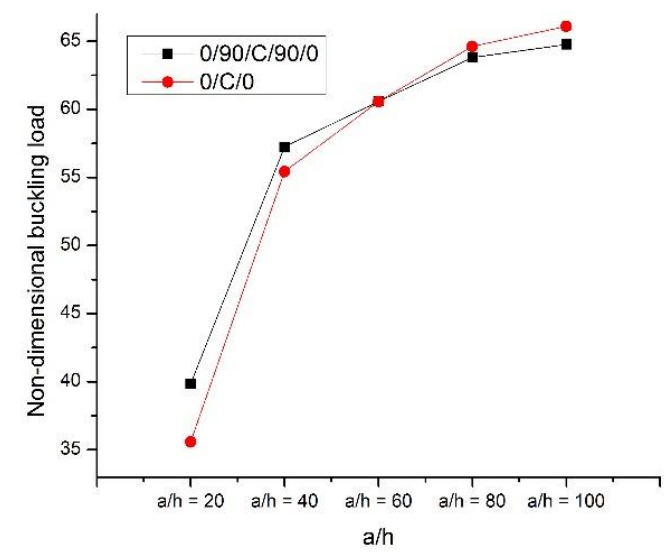

Fig. 6. Effect of a/h ratio on buckling of clamped sandwich panels $(a / b=1)$.

\section{CONCLUSIONS}

An FE model has been developed in ABAQUS. Its validation has been done by comparing the results from the literature. The validation is clearly showing that the developed FE model is capable of solving various buckling problems with precision and with a less cost. In this work, buckling behavior of sandwich panel having isotropic core and orthotropic faces has been studied with different end conditions, aspect ratios and thickness ratios. The following general conclusions are:

- Clamped sandwich panels having isotropic core and orthotropic faces have the highest buckling load.

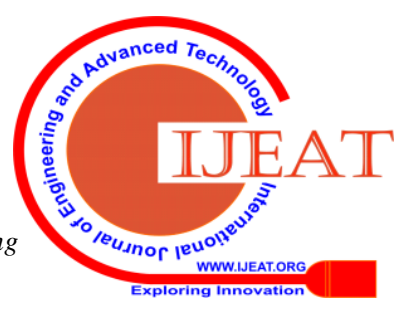


- With an increase in an aspect ratio of sandwich panel with isotropic core and orthotropic faces buckling load increases.

- With an increase in a/h ratio, buckling load of sandwich panel with isotropic core and orthotropic faces increases

\section{REFERENCES}

1. P. Poluraju and G. A. Rao, "Behaviour of 3D-Panels for Structural Applications Under General Loading: a State-of-the-Art," Int. J. Res. Engineering Technol., vol. 3, no. 16, pp. 173-181, 2014.

2. A. Einea, D. C. Salmon, G. J. Fogarasi, T. D. Culp, and M. K. Tadros, "State-of-the-Art of Precast Concrete Sandwich Panels," PCI J., vol. 36, no. 6, pp. 78-98, 1991.

3. N. Pokharel, and M. Mahendran, "Finite element analysis and design of sandwich panels subject to local buckling effects," Thin-walled struct., vol. 42, no 4, pp.589-611, 2004.

4. N. Pokharel and M. Mahendran, "Experimental investigation and design of sandwich panels subject to local buckling effects," J Constr Steel Res, vol 59, no 12, pp.1533-1552, 2003.

5. M. Taczała and W. Banasiak, "Buckling of I-core sandwich panels," $J$ Theor App Mech, vol 42, no 2, pp.335-348, 2004.

6. G.A. Kardomateas, "Global buckling of wide sandwich panels with orthotropic phases: an elasticity solution," In Sandwich Structures. Springer, Dordrecht, pp. 57-66, 2005.

7. H. Kolsters and D. Zenkert, "Buckling of laser-welded sandwich panels. Part 2: elastic buckling normal to the webs," Proc IME M J Eng Marit Environ, vol 220, no 2, pp.81-94, 2006.

8. A. Xu, T. Vodenitcharova, K. Kabir, E.A. Flores-Johnson and M. Hoffman, "Finite element analysis of indentation of aluminium foam and sandwich panels with aluminium foam core," Mat Sci Eng A-Struct., vol 599, pp.125-133, 2014.

9. A Chakrabarti, H. D. Chalak, M. A. Iqbal and A. H. Sheikh, "Buckling analysis of laminated sandwich beam with soft core." LAJSS, vol. 9 no 3, pp. 1-15, 2012.

10. S. Monika Sri, P. Polu Raju, Sanjay Deori, "Numerical Analysis of 3-D Sandwich Walls Under Blast Loading" IJRTE, Vol 7, no 6C2, pp. 799-803, 2019.

11. M.S. Manideep, A.K. Chaubey, M.L.S.R. Rao, "Experimental Investigation on Flexural Behaviour of Sandwich slabs with and without concealed beams,"IJRTE, Vol. 7, Issue-6C2, pp. 311-316, 2019.

12. A.K. Chaubey, S. Vishwakarma, A. Kumar, S. Fic, D.B. Hunek, "Transient response of rhombic laminates," Struct Eng Mech, vol 70, no 5, pp. 551-562, 2019.

13. A. Anish, A.K. Chaubey, A. Kumar,B. Kwiatkowski, D. Barnat-hunek and M.K. Widomski, "Bi-Axial Buckling of Laminated Composite Plates Including Cutout and Additional Mass." Materials, vol 12, no 11, pp.1750, 2019.

14. A.K. Chaubey, A. Kumar, S. Fic, D. Barnat-hunek and B. Sadowska-Buraczewska, "Hygrothermal Analysis of Laminated Composite Skew Conoids," Materials (Basel), vol 12, no 2, 225, 2019.

15. A. Kumar, C. Ishan, J. Ajay, K. Munise, D. Demirbas, S. Dey, Dual axis buckling of laminated composite skew hyperbolic paraboloids with openings, J. Brazilian Soc. Mech. Sci. Eng., vol 40, 490, 2018.

16. A.K. Chaubey, A. Kumar, and A. Chakrabarti, "Novel shear deformation model for moderately thick and deep laminated composite conoidal shell," Mech Based Des Struc., vol. 46, no. 5, pp. 650-668, 2018.

17. A.K. Chaubey, A. Kumar, and A. Chakrabarti, "Vibration of laminated composite shells with cutouts and concentrated mass," AIAA Journal, vol 56, no 4, pp.1662-1678, 2017.

18. A.K. Chaubey, A. Kumar, and S.S. Mishra, "Dynamic analysis of laminated composite rhombic elliptic paraboloid due to mass variation," J Aerospace Engg, vol 31, no 5, p.04018059, 2018.

19. A.K. Chaubey, A. Kumar, M.K. Widomski and D. Barnat-Hunek, "Behavior of laminated composite skew plates under different temperature variations," In AIP Conference Proceedings, vol. 2133, no. 1, p. 020011, 2019.

20. A.K. Chaubey, A. Kumar, B. Klimek, and D. Barnat-Hunek, "Thermal and moisture concentration effects on laminated composite hypars," In AIP Conference Proceedings, vol. 2133, no. 1, p. 020010, 2019.

21. A.K. Chaubey, A. Kumar, and A. Chakrabarti, "Static analyses of laminated rhombic conoids," Engg Comput., vol 36, no 4, pp.1346-1363, 2019.

22. A.K. Chaubey, C. Prakash, and A. Kumar, "Biaxial and shear buckling of laminated composite elliptic paraboloids with cutouts and concentrated mass," Mech Res Commun, vol. 94, pp.80-87, 2018.
23. SK.Fayaz, I.Siva Kishore, Ch.Mallika Chowdary, K.J. Brahmachari, "Numerical Analysis of Cold Formed Steel Compression Members Based on Buckling Profile Under Eccentric Loading," IJRTE, vol 7, Issue- 6C2, 2019.

24. E.V.V.S.N.Sai Kausik, I.Siva Kishore, N.Sandeep Kumar, Ch. Mallika Chowdary, "Behavior of Circular CFST Columns with Central Wood Piece Under Biaxial Loading," IJRTE, vol 7, Issue- 6C2, 2019.

25. B.L. Goli, H. K. Yerramasetty, L. Nagarathinam, and S. Nandam, "Analytical Study Of Buckling Restrained Braced Frames Under Lateral Loads Using Etabs," IJPAMS, vol 115 no 8, pp.431-436, 2017.

26. M. M. Kheirikhah, S.R.M Khalili and F. K. Malekzadeh, "Biaxial buckling analysis of soft-core composite sandwich plates using improved high-order theory," Eur J Mech A Solids vol 31, pp. 54-66, 2012.

\section{AUTHORS PROFILE}

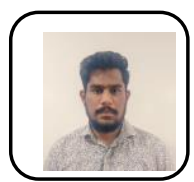

Saheel Arshad, is doing his Master of Technology in Structural Engineering at Koneru Lakshmaiah Education Foundation, Vaddeswaram, Guntur district, AP, India. His research interests include Sandwich panels, Buckling Analysis of RC structures.

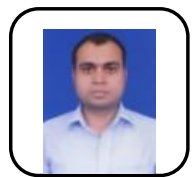

Abhay Kumar Chaubey, has completed his PhD from NIT Patna. He is working in Department of Civil Engineering, Koneru Lakshmaiah Education Foundation, Vaddeswaram, Guntur district, AP, India. His area of interest is sandwich plate/shell.

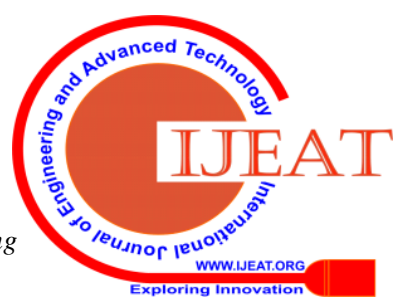

